You might find this additional information useful...

This article cites 30 articles, 5 of which you can access free at:

http://ajpregu.physiology.org/cgi/content/full/275/1/R212\#BIBL

This article has been cited by 14 other HighWire hosted articles, the first 5 are:

Cocoa-Related Flavonoids Inhibit CFTR-Mediated Chloride Transport across T84 Human Colon Epithelia

M. Schuier, H. Sies, B. Illek and H. Fischer

J. Nutr., October 1, 2005; 135 (10): 2320-2325.

[Abstract] [Full Text] [PDF]

Flavonoid metabolites and susceptibility of rat lipoproteins to oxidation

S. Benito, S. Buxaderas and M. T. Mitjavila

Am J Physiol Heart Circ Physiol, December 1, 2004; 287 (6): H2819-H2824.

[Abstract] [Full Text] [PDF]

The splanchnic metabolism of flavonoids highly differed according to the nature of the compound

V. Crespy, C. Morand, C. Besson, N. Cotelle, H. Vezin, C. Demigne and C. Remesy

Am J Physiol Gastrointest Liver Physiol, June 1, 2003; 284 (6): G980-G988.

[Abstract] [Full Text] [PDF]

Intestinal Uptake of Quercetin-3-Glucoside in Rats Involves Hydrolysis by Lactase Phlorizin Hydrolase

A. L. A. Sesink, I. C. W. Arts, M. Faassen-Peters and P. C.H. Hollman

J. Nutr., March 1, 2003; 133 (3): 773-776.

[Abstract] [Full Text] [PDF]

Comparison of the antioxidant effects of Concord grape juice flavonoids \{alpha\}-tocopherol on markers of oxidative stress in healthy adults

D. J O'Byrne, S. Devaraj, S. M Grundy and I. Jialal

Am. J. Clinical Nutrition, December 1, 2002; 76 (6): 1367-1374.

[Abstract] [Full Text] [PDF]

Medline items on this article's topics can be found at http://highwire.stanford.edu/lists/artbytopic.dtl

on the following topics:

Agriculture .. Fruits and Vegetables

Biochemistry .. Low-Density Lipoproteins

Oncology .. Oxidative Damage

Pharmacology .. Antioxidants

Medicine .. Diet

Physiology .. Rats

Updated information and services including high-resolution figures, can be found at:

http://ajpregu.physiology.org/cgi/content/full/275/1/R212

Additional material and information about American Journal of Physiology - Regulatory, Integrative and

Comparative Physiology can be found at:

http://www.the-aps.org/publications/ajpregu

This information is current as of September 8, 2010 .

The American Journal of Physiology - Regulatory, Integrative and Comparative Physiology publishes original investigations that illuminate normal or abnormal regulation and integration of physiological mechanisms at all levels of biological organization, ranging from molecules to humans, including clinical investigations. It is published 12 times a year (monthly) by the American Physiological

Society, 9650 Rockville Pike, Bethesda MD 20814-3991. Copyright () 1998 by the American Physiological Society. ISSN: 0363-6119, ESSN: 1522-1490. Visit our website at http://www.the-aps.org/. 


\title{
Plasma metabolites of quercetin and their antioxidant properties
}

\author{
CHRISTINE MORAND, VANESSA CRESPY, CLAUDINE MANACH, \\ CATHERINE BESSON, CHRISTIAN DEMIGNE, AND CHRISTIAN RÉMÉSY \\ Laboratoire des Maladies Métaboliques et des Micronutriments, Institut National de la Recherche \\ Agronomique de Clermont-Ferrand/ Theix, 63122 Saint-Genès-Champanelle, France
}

\begin{abstract}
Morand, Christine, Vanessa Crespy, Claudine Manach, Catherine Besson, Christian Demigné, and Christian Rémésy. Plasma metabolites of quercetin and their antioxidant properties. Am. J . Physiol. 275 (Regulatory Integrative Comp. Physiol. 44): R212-R219, 1998.-Quercetin is one of the most widely distributed flavonoids present in fruits and vegetables. The present experiments were performed on rats adapted for $3 \mathrm{wk}$ to a semipurified diet supplemented with $0.2 \%$ quercetin. The major part of the circulating metabolites of quercetin (91.5\%) are glucurono-sulfo conjugates of isorhamnetin (3'-O-methyl quercetin; $89.1 \pm 2.1 \mu \mathrm{M}$ ) and of quercetin $(14.7 \pm 1.7 \mu \mathrm{M})$; the minor part $(8.5 \%)$ is constituted by glucuronides of quercetin and its methoxylated forms $(9.6 \pm 2.3 \mu \mathrm{M})$. Conjugated dienes formation, resulting from $\mathrm{Cu}^{2+}$-catalyzed oxidation of rat very low density lipoproteins + low density lipoproteins (LDL), was effectively inhibited in vitro by conjugated metabolites of quercetin. These metabolites appeared to be four times more potent than trol ox in inhibiting LDL oxidation. Moreover, the plasma from rats adapted to a diet containing $0.2 \%$ quercetin exhibited a total antioxidant status markedly higher than that of control rats (+60\%). This study shows that ubiquitous quercetin is conjugated in vivo, yielding metabolites that exhibit antioxidant properties. Thus the health benefits of flavonoids in foods can be due to the antioxidant properties of their metabolites.
\end{abstract}

rat; conjugated metabolites; glucuronidation; sulfation; lowdensity lipoprotein oxidation

FLAVONOIDS ARE A GROUP of phenolic compounds that are diverse in chemical structure and characteristics. They occur naturally in fruit, vegetables, nuts, seeds, flowers, and bark and are an integral part of the human diet. Over 4,000 different flavonoids have been described, and they are categorized into flavonols, flavones, catechins, flavanones, anthocyanidins, and isoflavonoids. All these compounds are characterized by a phenyl benzo $(\gamma)$ pyrone-derived structure and they differ by 1) modifications of the nucleus, especially the pyronic cycle saturation, 2) the number and position of phenol functions, and 3) the degree of methylation and glycosylation, which affects various properties of these flavonoids, particularly their hydrophobicity (21).

Flavonoids are ingested daily in human diet; the consumption of 4-oxo-flavonoids has been estimated at $\sim 26 \mathrm{mg} /$ day in The Netherlands (13). Flavonoids have long been considered inert and nonessential for human health; however, in the last few years it has been shown that these compounds affect a wide variety of biological systems in mammals, exhibiting antioxidant, antiinflammatory, antiviral, antiproliferative, and anticarcinogenic effects $(23,25)$. Recently, much attention has been paid to their antioxidant properties and to their inhibitory role in various stages of tumor development in animal studies. Even if epidemiological studies failed to put forward an association between flavonoid consumption and cancer mortality, the intake of flavonols and flavones was inversely associated with coronary heart diseases (14); this could possibly be explained by the antioxidant effects of flavonoids.

Among flavonoids, flavonols seem particularly interesting because they are abundant in plant foods (12) and have most of the biological properties of flavonoids. In foods flavonols naturally occur as O-glycosides, with a sugar usually bound at the C-3 position (36). Only free flavonoids with no sugar molecule, the so-called aglycones, were thought to be able to pass through the gut wall. No enzyme that can split the predominantly $\beta$-glycosidic bonds is secreted in the gut or is present in the intestinal wall of mammals (10), so hydrolysis only occurs in the large intestine by microflora (1). Less is known about the absorption and metabolism of flavonoids in humans at the usual levels of dietary intake. Despite extensive bacterial metabolism, the absorption of flavonols in rats adapted to a diet containing $0.2 \%$ quercetin brings up to $\sim 100 \mu \mathrm{mol} / \mathrm{l}$ accumulation in blood plasma (20). In humans, the ingestion of fried onions containing quercetin glucosi des equivalent to 64 $\mathrm{mg}$ of quercetin aglycone led to a mean peak plasma level of quercetin of $650 \mathrm{nmol} / \mathrm{l}$ after $3 \mathrm{~h}$ (15).

In the liver, flavonoids and their metabolites may undergo modifications such as methylation or hydroxylations (11). The liver also synthesizes conjugated derivatives by coupling with a sulfate or a glucuronic acid molecule. Consequently there is an accumulation of various conjugated derivatives in the plasma of rats fed a diet containing quercetin or rutin $(19,20)$. The conjugated flavonoid derivatives are excreted in urine and bile, and the major route depends on the species. Even if the liver seems to be the main tissue involved in flavonoid metabolism, other tissues that contain conjugative enzymes, such as intestinal mucosa or kidneys, could al so be implicated $(11,38)$.

Quercetin is absorbed in humans and is only slowly eliminated throught the day (15). Thus quercetin could significantly contribute to the antioxidant defenses present in blood plasma. The aim of the present work was to 1) characterize in rats the circulating metabolites of quercetin and 2) test in vitro and in vivo the antioxidant capacities of these conjugated derivatives.

\section{MATERIALS AND METHODS}

\section{Animals and Diets}

Male Wistar rats used for the experiments weighed $\sim 170 \mathrm{~g}$. They were housed two per cage in temperature-controlled 
rooms $\left(22^{\circ} \mathrm{C}\right)$, with a dark period from 0900 to 2100 and access to food from 0900 to 1700 . Twenty-four rats were divided into two groups and adapted during 3 wk to semipurified diets: 1) a control diet and 2) a $0.2 \%$ quercetin diet; the detailed compositions of these diets are given in Table 1 . Animals were maintained and handled according to the recommendations of the Institut National dela RechercheAgronomique Institutional Ethics Committee, in accordance with decreeno. 87-848.

\section{HPLC Analysis}

Sampletreatment. Plasma or reaction mixture (for glucuronidation and sulfation studies) was spiked with $25 \mu \mathrm{M}$ of diosmetin, used as internal standard and acidified to $\mathrm{pH} 4.9$ with 0.1 vol of $0.58 \mathrm{M}$ acetic acid solution. Samples were incubated for $30 \mathrm{~min}$ at $37^{\circ} \mathrm{C}$ in the absence (unconjugated) or presence (total) of $5 \times 10^{6} \mathrm{U} / \mathrm{l} \beta$-glucuronidase and $2.5 \times 10^{5}$ $\mathrm{U} / \mathrm{l}$ sulfatase (final volume, $200 \mu \mathrm{l}$ ). The reactions were stopped by adding $7.5 \mathrm{vol}$ of acetone, and the resulting mixtures were centrifuged. Supernatants were evaporated to a volume equivalent to two times the initial volume of the samples (recovery $>85 \%$ ), then $20 \mu \mathrm{l}$ were injected and analyzed by HPLC. The amounts of conjugated derivatives were calculated by subtracting the unconjugated values from the total ones.

Chromatographic conditions. The HPLC system used consisted of an autosampler, an ultraviolet detector, and a software system that controlled all the equipment and carried out data processing. The system was fitted with a $5-\mu m C_{18}$ Hypersil based desactivated silicat analytic column (150 $\times$ $4.6 \mathrm{~mm}$ ID) (Life Sciences I nternational, Cergy, France). The ultraviolet detector was set at $370 \mathrm{~nm}$, and the mobile phase consisted of $73 \%$ solvent $A$ and $27 \%$ solvent $B$, where solvent $A=\mathrm{H}_{2} \mathrm{O} / \mathrm{H}_{3} \mathrm{PO}_{4}$ (99.5:0.5) and solvent $\mathrm{B}=$ acetonitrile. For deconjugated samples, elution was isocratic (flow rate 1.5 $\mathrm{ml} / \mathrm{min}$ ). To visualize and separate the conjugated metabolites of flavonols, the chromatographic conditions of elution were as follows (flow rate $1 \mathrm{ml} / \mathrm{min}$ ): $0-2 \mathrm{~min}, 85 \%$ solvent $A / 15 \%$ solvent $B ; 2-22$ min, $85 \%$ solvent $A / 15 \%$ solvent $B \rightarrow$ $60 \%$ sol vent $A / 40 \%$ solvent $B ; 22-24 \mathrm{~min}$, isocratic for $3 \mathrm{~min}$, then returned to initial conditions and equilibration for $8 \mathrm{~min}$.

In Vitro Assay of Flavonoid Glucuronidation

Intestinal and liver microsomes from rats adapted to the quercetin diet were prepared by differential ultracentrifuga-

\section{Table 1. Composition of diets}

\begin{tabular}{lcc}
\hline \hline & Control diet & Quercetin diet \\
\hline Wheat starch & 680 & 678 \\
Casein & 150 & 150 \\
Quercetin & 50 & 2 \\
Peanut oil & 60 & 50 \\
Mineral mixture & 10 & 60 \\
Vitamin mixture & 10
\end{tabular}

Values are $\mathrm{g} / \mathrm{kg}$ diet. Wheat starch and casein were from Louis François (Paris, France). Peanut oil was from Comptoir Industriel des Gléagineux (Genay, France). Mineral mixture (per kg of diet) was composed of the following: $15 \mathrm{~g} \mathrm{CaHPO}_{4}, 2.5 \mathrm{~g} \mathrm{~K}_{2} \mathrm{HPO}_{4}, 5 \mathrm{~g} \mathrm{KCl}, 5 \mathrm{~g}$ $\mathrm{NaCl}, 2.5 \mathrm{~g} \mathrm{MgCl}_{2}, 2.5 \mathrm{mg} \mathrm{Fe}_{2} \mathrm{O}_{3}, 125 \mathrm{mg} \mathrm{MnSO}_{4}, 0.2 \mathrm{mg} \mathrm{CuSO} \cdot 7 \mathrm{H}_{2}$ $\mathrm{O}, 100 \mathrm{mg} \mathrm{ZnSO} \cdot \cdot 7 \mathrm{H}_{2} \mathrm{O}$, and $0.4 \mathrm{mg} \mathrm{KI}$, purchased from Usine d'Alimentation Rationnelle (UAR) (Villemoisson, Epinay sur Orge, France). Vitamin mixture (per $\mathrm{kg}$ of diet) was composed of the following: 19,800 IU retinol, 2,500 IU cholecalciferol, 20 mg thiamine, $15 \mathrm{mg}$ riboflavin, $70 \mathrm{mg}$ niacin, $10 \mathrm{mg}$ pyridoxine, $0.05 \mathrm{mg}$ cobalamin, $800 \mathrm{mg}$ ascorbic acid, $170 \mathrm{mg}$ tocopherol, $40 \mathrm{mg}$ menadione, $100 \mathrm{mg}$ nicotinic acid, $1.36 \mathrm{~g}$ choline, $5 \mathrm{mg}$ folic acid, $50 \mathrm{mg}$ p-aminobenzoic acid, and $10 \mathrm{mg}$ biotin, purchased from UAR. tion at $105,000 \mathrm{~g}$ at $4^{\circ} \mathrm{C}$ for $1 \mathrm{~h}$. To prepare intestinal microsomes, mucosal scrapings were homogenized in ice-cold buffer of a composition similar to that used for liver homogenization $(50 \mathrm{mM}$ Tris. $\mathrm{HCl}, \mathrm{pH}$ 7.2, $100 \mathrm{mM}$ sucrose, $10 \mathrm{mM}$ EDTA, $2 \mathrm{mM}$ dithiothreitol, and $1 \mu \mathrm{M}$ leupeptin), except that trypsin inhibitor ( $25 \mathrm{mg} / 100 \mathrm{ml}$ ) was added to the buffer to prevent UDP-glucuronosyltransferaseinactivation by pancreatic enzymes. The final microsomal pellet was resuspended in a buffer containing 100 mM HEPES, pH 7.2, and 100 mM sucrose (supplemented with trypsin inhibitor for intestinal fractions) and kept in a frozen state at $-20^{\circ} \mathrm{C}$ until use. The final preparation was adjusted to have a final protein concentration of $\sim 5 \mathrm{mg} / \mathrm{ml}$, measured according to the Pierce bicinchoninic acid (BCA) protein reagent kit (Interchim, Montluçon, France).

I ncubations were carried out as follows. I n a final volume of $750 \mu \mathrm{l}, 540 \mu \mathrm{l}$ of buffer (75 mM HEPES and $10 \mathrm{mM} \mathrm{MgCl}$, $\mathrm{pH}$ 7.3), $50 \mu$ l of UDP-glucuronic acid ( $4.5 \mathrm{mM}$ final) and $100 \mu \mathrm{l}$ of microsomal suspension (50 $\mu \mathrm{g}$ protein) were activated in situ by $60 \mu \mathrm{l}$ of a $0.2 \%$ solution of Triton X-100. The reaction was started by the addition of $2 \mu \mathrm{l}$ of an aglycone solution (18.75 $\mathrm{mM}$ in DMSO). I ncubations were performed at $37^{\circ} \mathrm{C}$ for $3 \mathrm{~h}$, then aliquots of the reaction mixture were taken and treated (with or without $\beta$-glucuronidase/sulfatase) for HPLC analysis, exactly as described above.

\section{In Vitro Assay for Flavonoid Sulfation}

Fresh liver was homogenized in 3 vol of ice-cold $0.1 \mathrm{M}$ Tris $\cdot \mathrm{HCl}, \mathrm{pH} 7.2$, and $0.25 \mathrm{M}$ sucrose. The homogenate was centrifuged for $20 \mathrm{~min}$ at $12,500 \mathrm{~g}$, and the supernatant was further centrifuged at $105,000 \mathrm{~g}$ for $1 \mathrm{~h}$. The final protein concentration in the cytosolic extract was $\sim 25 \mathrm{mg} / \mathrm{ml}$.

The in vitro sulfation of quercetin and isorhamnetin ( 3 '-Omethyl quercetin) by cytosolic sulfotransferases of rat liver was followed using $3^{\prime}$-phosphoadenosine 5'-phosphosulfate (PAPS) as the sulfate donor. The standard assay mixture consisted of $20 \mu \mathrm{M}$ of the flavonoid substrate dissolved in DMSO (final concentration in the assay 0.4\%), $25 \mu \mathrm{M}$ PAPS, 5 $\mathrm{mM} \mathrm{MgCl}_{2}$, and the enzyme protein $(0.5 \mathrm{mg})$ in $25 \mathrm{mM}$ Tris. $\mathrm{HCl}$ buffer, $\mathrm{pH} 7.2$, in a total volume of $500 \mu \mathrm{l}$. The reaction was initiated by addition of the cytosolic extract and incubated for $60 \mathrm{~min}$ at $37^{\circ} \mathrm{C}$, and then aliquots of the reaction mixture were taken and processed as described for HPLC analysis.

\section{Rat Lipoprotein Preparation}

Blood from eight rats (weighing $\sim 150 \mathrm{~g}$ ) fed a standard nonpurified diet (AO3 pellets; Usine d'Alimentation Rationnelle, Villemoisson/Orge, France) was collected into tubes containing EDTA ( $1 \mathrm{~g} / \mathrm{l})$. Equal volumes of plasma samples were pooled for lipoprotein separation. Because the LDL fraction is poorly represented in rat plasma, a very low density lipoprotein (VLDL) + low-density lipoprotein (LDL) fraction was isolated. Samples (protected by EDTA, $1 \mathrm{~g} / \mathrm{l}$ ) were overlayered with $0.15 \mathrm{M} \mathrm{NaCl}$ (density = $1.006 \mathrm{~kg} /$ ), and chylomicrons were discarded after two 30 min-long centrifugations at $12,000 \mathrm{~g}$ and $15^{\circ} \mathrm{C}$. To isolate the VLDL $+\mathrm{LDL}$ fraction, the remaining plasma was adjusted to a density of $1.050 \mathrm{~kg} / \mathrm{l}$ with solid $\mathrm{KBr}$. Centrifugation was performed at $100,000 \mathrm{~g}$ and $15^{\circ} \mathrm{C}$ for $20 \mathrm{~h}$. The VLDL + LDL fraction was then washed by a further period of ultracentrifugation at the same density.

\section{Measurement of the Oxi dative Susceptibility of Lipoproteins}

Before oxidation experiments, the purified lipoprotein fraction was dialyzed against deoxygenated PBS $(10 \mathrm{mmol} / \mathrm{l}, \mathrm{pH}$ 7.4) for $24 \mathrm{~h}$. The final protein concentration (BCA protein 
reagent kit, Pierce) in lipoprotein fraction was adjusted to 20 $\mathrm{mg} / \mathrm{l}$. Lipoprotein concentration was calculated from the mass of protein plus individual lipids. The lipoprotein fraction was supplemented with ethanolic solutions of aglycones or with the aqueous solutions of the conjugated derivatives of these molecules. Oxidation was initiated by the addition of freshly prepared $\mathrm{CuSO}_{4}$ solution (10 $\mu \mathrm{mol} / \mathrm{l}$ final concentration) at $37^{\circ} \mathrm{C}$. The kinetics of lipoprotein oxidation were determined by continously monitoring at $37^{\circ} \mathrm{C}$ the changes in absorbance at $234 \mathrm{~nm}$, corresponding to dienes formation, on an U vikon 930 spectrophotometer (8).

\section{Determination of Total Antioxidant Status}

Total antioxidant status was assayed on heparinized plasma samples using the total antioxidant status kit (Randox Laboratories, Roissy, France), according to specified recommendations. The principle of this assay is based on the incubation of 2,2'-azino-bis(3-ethylbenzthiazol ine sulfonate) (ABTS) with a peroxydase and $\mathrm{H}_{2} \mathrm{O}_{2}$ to produce the radical cation ABTS*+, leading to the appearance of a blue-green color, which is measured at $600 \mathrm{~nm}$. The antioxidant capacity (expressed as trolox equivalent) of the sample was inversely proportional to the coloration intensity.

\section{Statistics}

Values are means $\pm S E$, and significance of the differences between mean values was determined by one-way ANOVA coupled with the Student-Newman-Keuls multiple-comparison test. Values of $\mathrm{P}<0.05$ were considered significant.

\section{RESULTS}

\section{Circulating Metabolites of Quercetin}

The chromatographic conditions were adapted to separate the circulating conjugated metabolites (see MATERIALS AND METHODS); with this gradient elution procedure, quercetin, isorhamnetin (3'-O-methyl quercetin), and tamarixetin (4'-O-methyl quercetin) were eluted at 15.7, 19.2, and $19.8 \mathrm{~min}$, respectively.

Figure 1, A and B, shows representative chromatograms of the plasma from control rats and from rats adapted to a $0.2 \%$ quercetin diet. The HPLC profile from rats adapted to the quercetin diet is characterized by: the absence of quercetin and the presence of three unidentified peaks, noted 1,2 , and 3 (retention times: $6.2,7.1$, and $12.9 \mathrm{~min}$ ), corresponding to the conjugated metabolites of quercetin. These metabolites had spectra (from 250 to $450 \mathrm{~nm}$ ) that fitted with flavonoid structure (data not shown). On the other hand, the HPLC profile for control rats did not show any trace of such metabolites.

The $\beta$-glucuronidase treatment of plasma from rats adapted to the quercetin diet (Fig. IC) revealed that some circulating metabolites corresponded to glucuronated forms of quercetin $(5.4 \pm 0.8 \mu \mathrm{M})$, isorhamnetin $(1.2 \pm 0.4 \mu \mathrm{M})$, and tamarixetin $(3.0 \pm 1.1 \mu \mathrm{M})$. However, two major and unidentified peaks (4 and 5) were also recovered after the action of $\beta$-glucuronidase (retention time $=12.23$ and $12.74 \mathrm{~min}$; Fig. 1C). Moreover, when the plasma was treated in the presence of $\beta$-glucuronidase plus sulfatase (Fig. 1D), these latter peaks ( 4 and 5) practically disappeared, showing that they corresponded to sulfated derivatives, whereas those of quercetin $(20.1 \pm 2.5 \mu \mathrm{M})$ and isorhamnetin $(93.3 \pm 2.1 \mu \mathrm{M})$ appeared.

These data showed that in rats fed a quercetin diet the glucurono-sulfo derivatives of isorhamnetin (89.1 \pm $2.1 \mu \mathrm{M})$ and of quercetin $(14.7 \pm 1.7 \mu \mathrm{M})$ are the major circulating forms $(91.5 \%)$, whereas glucuronides of quercetin and of its methoxylated forms are the other minor metabolites (8.5\%).

\section{In Vitro Studies on Glucuronidation of Quercetin and I sorhamnetin}

The capacity of rat liver and cecal microsomal fractions to transfer in vitro glucuronic acid from UDPglucuronic acid to quercetin and isorhamnetin has been tested using microsomal fractions obtained from rats adapted to the $0.2 \%$ quercetin diet $(n=6)$.

After the hepatic microsomal glucuronoconjugation of $50 \mu \mathrm{M}$ quercetin, the reaction products were analyzed by HPLC using the gradient elution procedure. Four metabolites of quercetin, labeled $a, b, c$, and d according to their increasing hydrophobicity, were present in the sample (Fig. 2A). Microsomes isolated from the cecal wall also exhibited an UDP-glucuronyl transferase activity and the chromatographic profile (Fig. 2B) presented the same four peaks (a, b, c, and d) as those obtained with liver microsomal fractions; however, the relative amounts of each peak were different. In both conditions, the reaction of glucuronidation was not complete and the capacity of the cecal wall to metabol ize quercetin to glucurono conjugates ( $83 \pm 3 \%$ ) appeared significantly greater than that of liver $(69 \pm 2 \%)$.

As for quercetin, the hepatic and cecal microsomal glucuronidation of isorhamnetin led to quite similar chromatographic profiles (Fig. 3, A and B), except for the relative amount of each peak. Because of their higher hydrophobicity, the four glucuronoconjugates of isorhamnetin $\left(a^{\prime}, b^{\prime}, c^{\prime}\right.$, and $\left.d^{\prime}\right)$ presented greater retention times than those of quercetin. Moreover, as for quercetin, the conversion of isorhamnetin to glucurono derivatives was slightly more efficient with microsomes from cecal wall $(87 \pm 4 \%)$ than with microsomes from liver $(78 \pm 2 \%)$. This result suggests that in vivo the cecal wall could play a noticeable role in flavonol glucuronidation.

\section{In Vitro Assay for Sulfation of Quercetin and I sorhamnetin}

Liver cytosolic extracts have been prepared to test their capacity to produce sulfoderivatives from quercetin and isorhamnetin. As it was previously found (31), our experiments showed that the hepatic phenolsulfotransferase involved in the sulfation of quercetin was sensitive to substrate inhibition (for concentration $>35$ $\mu \mathrm{M}$, data not shown). Consequently, present experiments have been performed using $25 \mu \mathrm{M}$ of quercetin or isorhamnetin. The in vitro sulfation of these compounds led, for each of them, to the formation of three sulfoconjugates (Fig. 4, A and B); the corresponding peaks were noted $e, f$, and $g$ for quercetin and $e^{\prime}, f^{\prime}$, and 

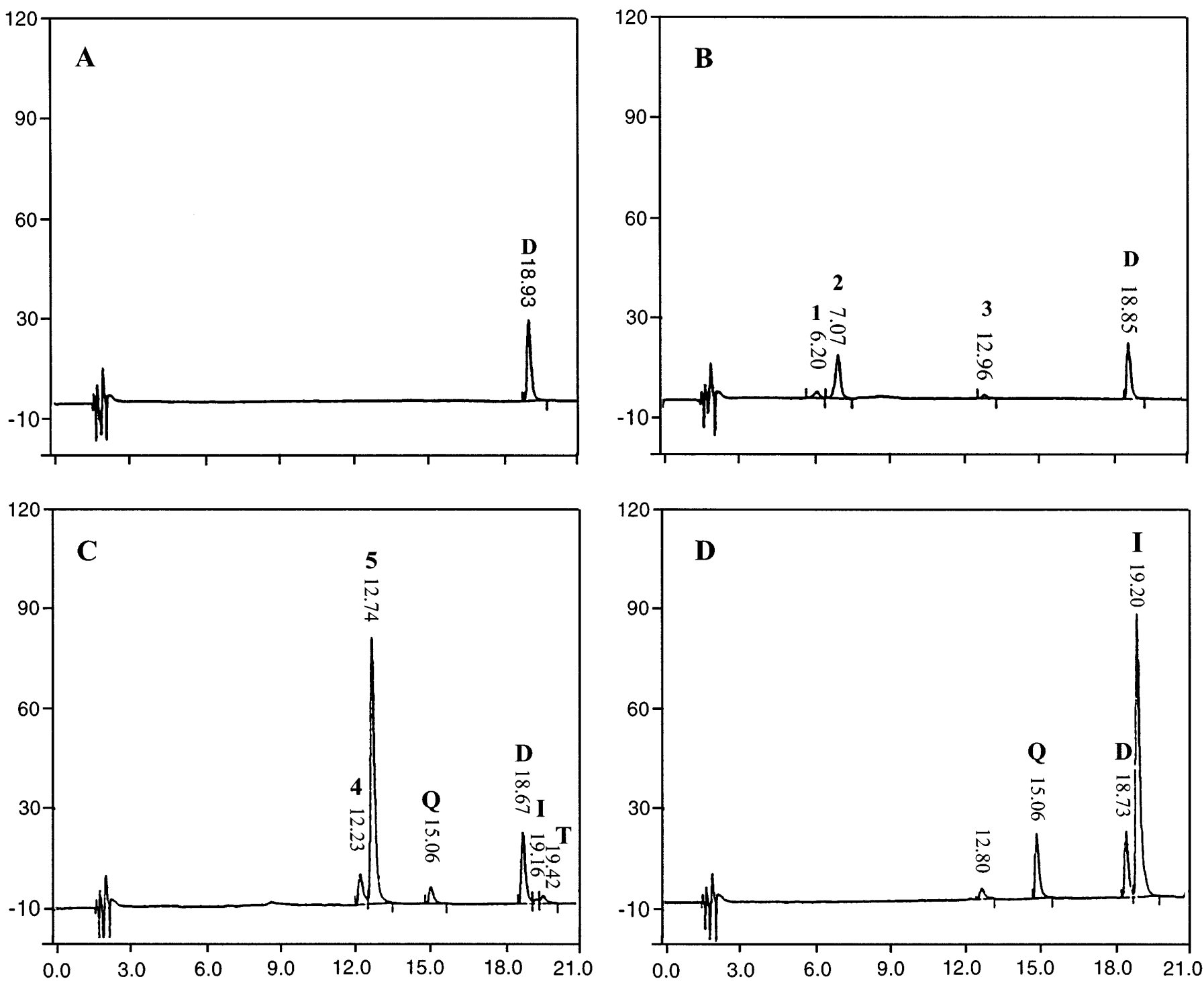

Fig. 1. Representative HPLC chromatograms of plasma from control rat (A) and from rat adapted to a $0.2 \%$ quercetin diet (B) and HPLC profiles resulting from treatment of plasma of rats adapted to quercetin diet with $\beta$-glucuronidase (C) or with $\beta$-glucuronidase/sulfatase (D). D, diosmetin (internal standard); Q, quercetin; I, isorhamnetin; T, tamarixetin. 1-5, conjugated metabolites.

$\mathrm{g}^{\prime}$ for isorhamnetin. Among these peaks, the last one (namely $g$ and $g^{\prime}$ ) was markedly higher than the others.

The chromatographic profiles obtained after the sulfation of quercetin (Fig. 4A) and isorhamnetin (Fig. 4B) have been compared with that of the plasma treated with $\beta$-glucuronidase (Fig. 1C). Taking into account the respective relative retention times compared with diosmetin, it appears that peaks 4 and 5, resulting from the hydrolysis of plasma quercetin metabolites by a $\beta$-glucuronidase, exhibit perfect coincidence with the sulfoconjugates of quercetin, $f$ and $g$, obtained in vitro. Moreover, peaks $f^{\prime}$ and $g^{\prime}$, corresponding to the sulfoderivatives of isorhamnetin, were contained in the large peak (5) resulting from the hydrolysis of the plasma by a $\beta$-glucuronidase. These data show that the two large peaks ( 4 and 5 ) resulting from the hydrolysis of plasma by a $\beta$-glucuronidase corresponded to at least three different forms of sulfoconjugates.

\section{Antioxidant Properties of the Conjugated F orms of Quercetin}

Theantioxidant properties of quercetin and its conjugated derivatives have been studied by following the formation (at $234 \mathrm{~nm}$ ) of conjugated dienes on rat VLDL + LDL fractions after induction of the oxidation with $\mathrm{CuSO}_{4}$. These experiments were performed using quercetin glucuronides, obtained via an in vitro proce dure (the efficiency of glucuronidation was 96\%). Because the in vitro sulfation of quercetin provided insufficient amounts of sulfoconjugates, the assays on their antioxidant effects were realized using a sulfoderivative commercially available (quercetin-3-O-sulfate).

Figure 5 shows that quercetin increased, in a concentration-dependent manner, the lag phase of conjugated diene formation: $+130 \mathrm{~min}$ at $0.25 \mu \mathrm{M}$ and $+255 \mathrm{~min}$ at 


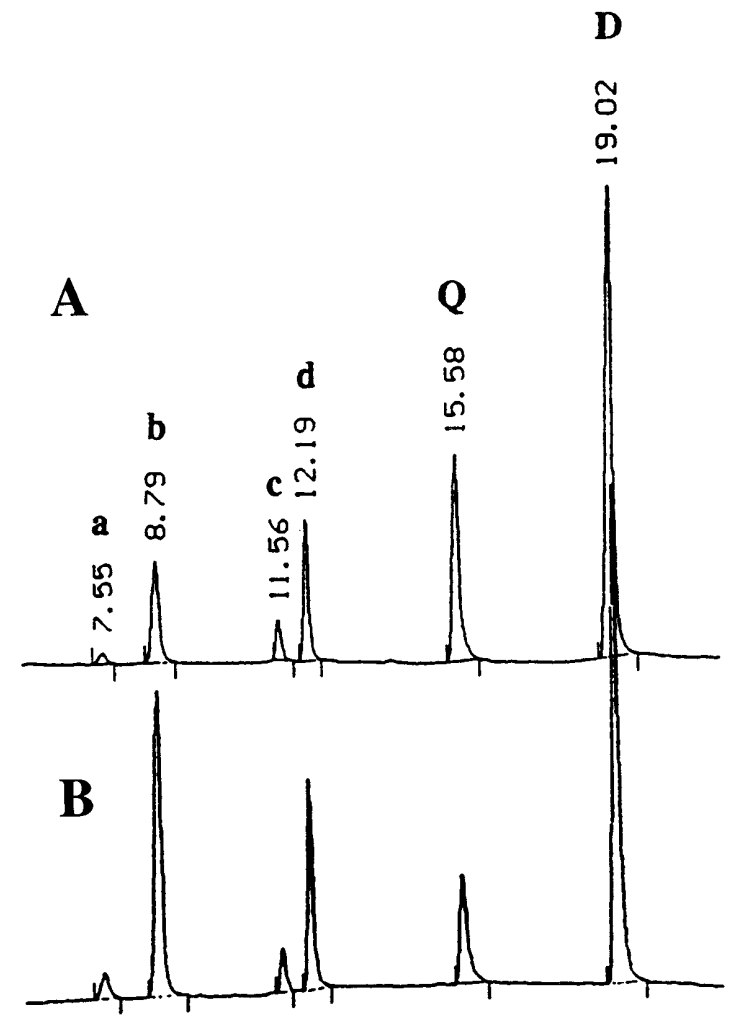

Fig. 2. RepresentativeHPLC chromatograms obtained after glucuronidation of $50 \mu \mathrm{M}$ quercetin with microsomal preparations from liver (A) and from cecal wall (B). a-d, glucuronide derivatives.

$0.5 \mu \mathrm{M}$. When present at $0.5 \mu \mathrm{M}$, quercetin glucuronides or quercetin-3-O-sulfate also significantly delayed copper-induced lipoprotein oxidation (+100 min or $+185 \mathrm{~min}$, respectively); however, the magnitude of their effects was lower than that of the aglycone. The simultaneous presence of $0.25 \mu \mathrm{M}$ quercetin glucuronides and $0.25 \mu \mathrm{M}$ quercetin-3-O-sulfate induced an inhibition of lipoprotein oxidation of the same magnitude as that observed with $0.25 \mu \mathrm{M}$ quercetin. It could be noted that, even if all these compounds significantly prolonged the lag phase, they did not affect the propagation rate of VLDL + LDL oxidation. Figure 6 shows that, when present at $0.5 \mu \mathrm{M}$, isorhamnetin delayed the onset of the propagation phase $\sim 75 \mathrm{~min}$, so it was less potent than quercetin (even when present at 0.25 $\mu \mathrm{M}$ ). As in quercetin, the glucuronides of isorhamnetin at $0.5 \mu \mathrm{M}$ or $1 \mu \mathrm{M}$ significantly delayed copper-induced lipoprotein oxidation ( 35 or $65 \mathrm{~min}$, respectively). These whole data show that, in vitro, the glucuronide or sulfate forms of quercetin and isorhamnetin exhibit a substantial protective effect on lipoprotein oxidation.

The antioxidant properties of quercetin and its conjugates were compared with those of trolox (a watersoluble form of vitamin E) using the present in vitro lipoprotein oxidation model. For each compound, I $C_{50}$ relative to a control was determined according to the specifications detailed in Table 2 . In agreement with the above results, the $\mathrm{IC}_{50}$ for the aglycone was generally lower than those of their glucuronides or sulfate forms (Table 2); however, these conjugates were four times more potent than trolox to inhibit lipoprotein oxidation.

\section{Determination of Total Antioxidant Status}

Experiments were performed on plasma from rats fed a control diet or a diet supplemented with $0.2 \%$ quercetin. It appeared that the total antioxidant status of the plasma from rats fed the quercetin diet $(0.963 \pm$ $0.031 \mu \mathrm{M}$ ) was markedly higher than the total antioxidant status of control plasma $(0.605 \pm 0.025 \mu \mathrm{M})$ (Fig. 7). This interesting result shows that the circulating metabolites of quercetin possess antioxidant properties.

\section{DISCUSSION}

The present study shows that in rats adapted to a diet containing $0.2 \%$ quercetin, the circulating metabolites were not quercetin itself but glucurono and/or sulfo conjugates. The enzymatic hydrolysis of the conjugated metabolites yielded chiefly isorhamnetin (the 3'-O-methylated form of quercetin) (80\%) and, in lesser part, quercetin (20\%). This particularly high level of isorhamnetin is in accordance with the high capacity of the liver to methylate quercetin (38). The extensive O-methylation of quercetin, in addition to other conjugation reactions such as glucuronide and sulfate forma-

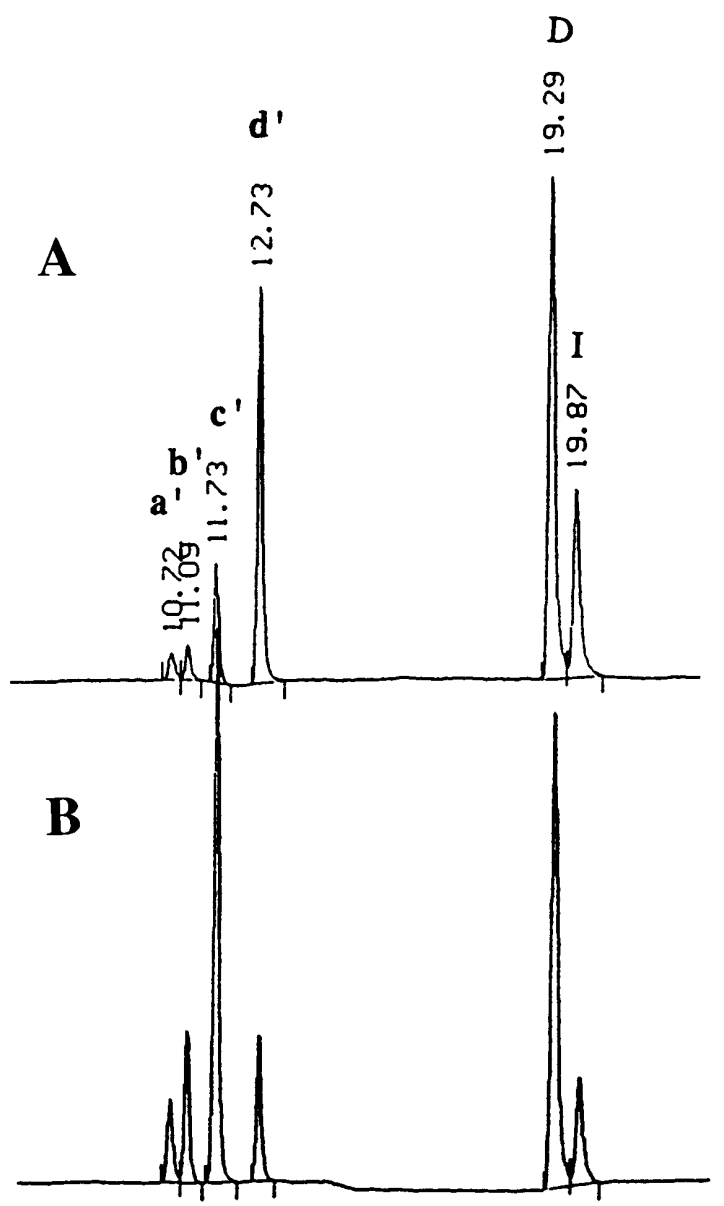

Fig. 3. Representative HPLC chromatograms obtained after glucuronidation of $50 \mu \mathrm{M}$ isorhamnetin with microsomal preparations from liver (A) and cecal wall (B). $a^{\prime}-d^{\prime}$, glucuronide derivatives. 



Fig. 4. Representative HPLC chromatograms obtained after in vitro sulfation of $25 \mu \mathrm{M}$ quercetin (A) or $25 \mu \mathrm{M}$ isorhamnetin (B). eg, sulfoderivatives of quercetin; $\mathrm{e}^{\prime}-\mathrm{g}^{\prime}$, sulfo-derivatives of isorhamnetin.

tion, may well be a major cause for thelack of toxicity of these compounds (6). Moreover, conjugation improves the water solubility of flavonoids and consequently favors their elimination.

A previous study performed on the hepatic microsomal glucuronidation of some flavonoids (3) reported that this important dass of natural compounds might be conjugated by a specific isoform of UDP-gluauronosyl transferase. The



Fig. 5. Rate of formation of conjugated dienes in rat very low density lipoprotein (VLDL) + low-density lipoprotien (LDL) fractions in presence of quercetin or its conjugated derivatives. Formation of conjugated dienes, induced in presence of $10 \mu \mathrm{M} \mathrm{Cu}{ }^{2+}$, was determined by continously monitoring changes in absorbance at $234 \mathrm{~nm}$.

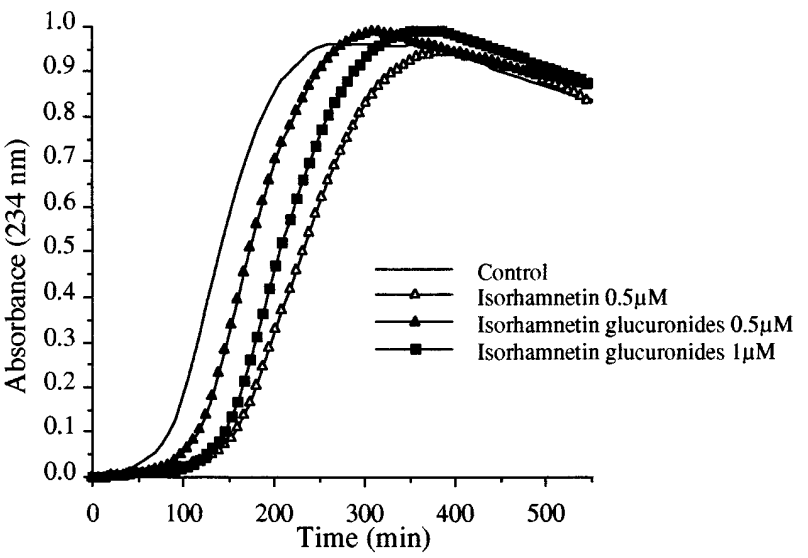

Fig. 6. Rate of formation of conjugated dienes in rat VLDL + LDL fractions in presence of isorhamnetin or its glucuronides. Experimental procedure was similar to that reported in Fig. 5.

liver does not constitute the unique site for flavonol glucuronidation because the present study shows a greater activity of glucuronidation in the cecal wall than in the liver. This result is in accordance with a recent study that reported that the in vivo glucuronidation of an isoflavone (genistein) occurred in the intestinal wall rather than in liver (29). The hepatic and cecal activity of quercetin glucuronidation led to the formation of the same glucuronides; however, the relative amount of each glucuronide depended on thetissue.

Sulfation constitutes another important pathway for phenolic compound conjugation. Although cytosolic sulfotransferases are present in numerous tissues, the highest level is found in theliver (26). The sulfation of quercetin by perfused rat liver gave two double conjugates, containing sulfateand glucuronicadid, and onesulfatederivative (31). This study is in agreement with our in vitro experiments, performed with liver cytosolic extracts, showing that the sulfation of quercetin led totheformation of threedifferent compounds. Moreover, some of them could correspond to sulfated derivatives resulting from the hydrolysis of circulating metabolites by a $\beta$-glucuronidase.

Although the possibilities of glucuronidation and sulfation of flavonols are numerous, it is quite striking to find only three peaks on HPLC analysis, corresponding to the plasma metabolites of quercetin. Two of them have retention times corresponding to multiconjugated metabolites [containing both sulfate(s) and glucuronic acid(s)] of isorhamnetin and quercetin. However, our

Table 2. Comparison of in vitro antioxidant effectiveness of quercetin derivatives and trolox

\begin{tabular}{lc}
\hline \hline \multicolumn{1}{c}{ Compound } & $\mathrm{IC}_{50}, \mu \mathrm{M}$ \\
\hline Trolox & 0.680 \\
Quercetin & 0.065 \\
Quercetin glucuronides & 0.173 \\
Quercetin-3-O-sulfate & 0.165
\end{tabular}

Antioxidants were added in duplicate at various concentrations to $15 \mu \mathrm{g} / \mathrm{ml}$ of lipoproteins in a pH 7.4 buffer with $10 \mu \mathrm{M}$ cupric ion for a period of $8 \mathrm{~h}$ at $37^{\circ} \mathrm{C}$. Lipid peroxydation was measured after diene formation at $234 \mathrm{~nm}$ vs. control with no antioxidant added. I $\mathrm{C}_{50}$ was determined graphically. 


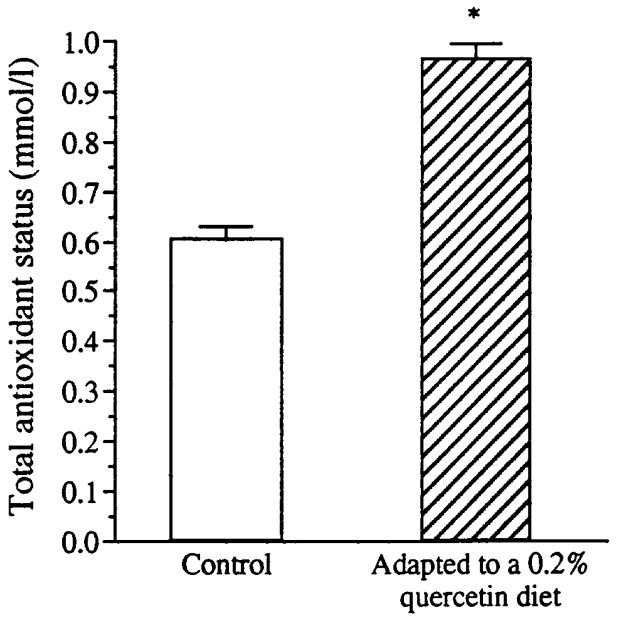

Fig. 7. Determination of total antioxidant status in rat plasma Plasma samples were withdrawn from rats adapted to standard diet (control) or to diet containing $0.2 \%$ quercetin. Then total antioxidant status was measured in plasma using Randox test. Values are means $\pm \mathrm{SE}, \mathrm{n}=10$ rats in each group, $* \mathrm{P}<0.05 \mathrm{vs}$. control.

chromatographic conditions were not adapted to separate each of these metabolites. Moreover, it could be noted that the peaks corresponding to the circulating conjugated metabolites of quercetin are quite small compared with the aglycone equivalents $(\sim 110 \mu \mathrm{M})$. This could be due to a marked decrease of the molar extinction coefficient value consecutive to the multiple conjugation of the molecules. Even if direct data arenot available, this hypothesis could be supported by the difference in the molar extinction coefficients observed between quercetin-3-rutinoside $(17,000 \pm 265 \mathrm{M} / \mathrm{cm})$ and quercetin $(22,362 \pm 451 \mathrm{M} / \mathrm{cm})$.

Even if the conjugated derivatives of quercetin constitute elimination forms that are recovered in bile and urine (22), these molecules could retain biological effects. In this view, it has been shown that the pharmacological activity of a conjugate may be higher than that of the parent compound (24). Moreover, the quercetin conjugate obtained by the addition of a succinyl-inositolphosphate moiety on quercetin has antiproliferative and cytotoxic activities identical to those of quercetin toward cultured human carcinoma cells (4).

Because of their structure, polyphenols could tend to accumulate at the water-lipid interfaces, and therefore they could constitute interesting agents to protect LDLs and cellular membranes from oxidative damages. Increasing evidence suggests that the oxidative modification to LDLs, and possibly other lipoproteins, is involved in atherogenesis $(30,37)$. Natural antioxidants that prevent or inhibit oxidative damage to LDLs may beneficially influence atherogenesis. Flavonoids have antioxidant activity in a variety of in vitro assay systems (6), and there is evidence that several flavonoids can inhibit oxidative modification of $\operatorname{LDLs}(7,9$, $20,34)$. According to Terao et al. (32), it is likely that aglycones (quercetin or catechin) are localized near the surface of phosphol ipid bilayers suitable for scavenging aqueous oxygen radicals, and thereby they prevent the consumption of lipophilic $\alpha$-tocopherol. The capacity to bind the phospholipid bilayer is not exclusive to the aglycones because the same phenomenon has been described for quercetin monoglucosides (18). Moreover, quercetin as its glucosidic form (rutin) has been shown to bind LDLs, and this could constitutea mechanism by which these compounds act as antioxidant agents (35).

Considering that the circulating forms of flavonoids are not the aglycones (22), it would be interesting to test the capacity of quercetin glucuronides and sulfates to enhance the resistance of rat VLDL + LDL to oxidation in rats. These experiments have shown that the conjugated derivatives of quercetin significantly delayed the $\mathrm{Cu}^{2+}$-induced oxidation of lipoproteins; however, the magnitude of this inhibition was about one-half that measured with the aglycone. A previous study demonstrated that flavonoid glucosides possess lower peroxyl radical-scavenging activity than corresponding aglycones (18). An alternative for the superiority of quercetin may arise from the difference of polarity between glycosides or conjugated derivatives and their aglycones. Quercetin is, rather, a lipophilic antioxidant compared with its glycosides or conjugates and seems to interact with the polar head of phospholipid bilayers by locating near the surface of membranes (7). This location may be favorable for the trap of peroxyl radicals originating from the aqueous phase. In contrast, quercetin glucosides or conjugated derivatives are more hydrophilic and likely distributed in water phase. Using an in vitro lipoprotein oxidation model, the conjugated derivatives of quercetin appeared to be more powerful antioxidants than the water-soluble form of vitamin E, suggesting that the circulating metabolites of naturally occuring flavonols could play an important role in the protection of lipoproteins in vivo.

Flavonoids can inhibit lipid peroxidation in vitro by acting either as free radical scavengers or as metalchelating agents $(2,5,16,28)$. In our experiments, the molar ratio of $\mathrm{Cu}^{2+}$ to conjugated derivatives of quercetin was 20:1; therefore it is unlikely that the extent of the inhibition is primarily due to copper binding. Because the conjugated forms of quercetin are watersoluble flavonoids, they could prevent LDL oxidation by taking up the water-soluble free radicals generated by copper through the Fenton reaction, and therefore they could decrease the consumption of the LDL antioxidant contained in the lipid-water interface. Furthermore, it has been shown that a flavonoid-rich extract, like pure flavonoids, increases LDL resistance to oxidation by decreasing consumption of vitamin $E(27,33)$. The circulating metabolites of quercetin could also exert antioxidant properties, as shown by the higher total antioxidant status of the plasma from rats adapted to a diet supplemented by quercetin than those receiving a control diet. In the same way, it has been reported that the in vitro antioxidant activity of the rat serum was enhanced in the presence of quercetin in the diet (17).

\section{Perspectives}

This study shows that ubiquitous quercetin, found in fruits and vegetables, is conjugated in vivo and that its circulating derivatives, by inhibiting LDL oxidation, should contribute to the antioxidant pool in the blood 
and thus slow down atherosclerosis processes. Further studies performed to determine the mechanisms of the beneficial effects of flavonoids in foods on human health should take into account the complexity of their circulating metabolites.

Address reprint requests to $C$. Morand.

Received 17 November 1997; accepted in final form 26 March 1998.

\section{REFERENCES}

1. Bokkenheuser, V. D., C. H. L. Shackleton, and J . Winter. Hydrolysis of dietary flavonoid glycosides by strains of intestinal Bacteroi des from humans. Biochem. J . 248: 953- 956, 1987.

2. Bors, W., W. Heller, C. Michel, and M. Saran. Flavonoids as antioxidants: determination of radical-scavenging efficiencies. Methods Enzymol. 186: 343- 355, 1990.

3. Boutin, J . A., F. Meunier, P. H. Lambert, P. Hennig, D. Bertin, B. Serkiz, and J . P. Volland. In vivo, and in vitro glucuronidation of the flavonoid diosmetin in rats. Drug Metab. Dispos. 21: 1157-1166, 1993.

4. Calias, P., T. Galanopoulos, M. Maxwell, A. Khayat, D. Graves, H. N. Antoniades, and M. d'Alarcao. Synthesis of inositol 2-phosphate-quercetin conjugates. Carbohydr. Res. 292: 83-90, 1996.

5. Cook, N. C., and S. Samman. Flavonoids-chemistry, metabolism, cardioprotective effects and dietary sources. J . Nutr. Biochem. 7: 66-76, 1996.

6. Das, A., J . H. Wang, and E.J . Lien. Carcinogenicity, mutagenicity and cancer preventing activities of flavonoids: a structure system-activity relationships (SSAR) analysis. In: Progress in Drug Research, edited by E. J ucker. Basel, Switzerland: Birkhauser Verlag, 1994, vol. 42, p. 133- 166.

7. De Whalley, C. V., S. M. Rankin, J . R. S. Hoult, W. J essup, and D. S. Leakes. Flavonoids inhibit the oxidative modification of low density lipoproteins by macrophages. Biochem. Pharmacol. 39: 1743-1750, 1990.

8. Esterbauer, H., G. Striegl, H. Puhl, and M. DieberRotheneder. Continuous monitoring of in vitro oxidation of human low density lipoprotein. Free Radic. Res. Commun. 6: 57-75, 1989.

9. Frankel, E. N., J . Kanner, J . B. German, E. Parks, and J . E. Kinsella. Inhibition of oxidation of human low-density lipoprotein by phenolic substances in red wine. Lancet 341: 454-457, 1993.

10. Griffiths, L. A. Mammalian metabolism of flavonoids, In: The Flavonoids: Advances in Research, edited by J. B. Harborne and T. J . Marbry. London, UK: Chapman and Hall, 1982, p. 681-718.

11. Hackett, A. M. The metabolism of flavonoid compounds in mammals. In: Plant Flavonoids in Biology and Medicine. Biochemical Pharmacological and Structure Activity Relationships, edited by V. Cody, E. Middleton, J r., and J. B. Harborne. New York: Liss, 1986, p. 177- 194.

12. Herrmann, K. Flavonols and flavones in food plants: a review. J Food Technol. 11: 433-438, 1976.

13. Hertog, M. G. L., E. J . M. Feskens, P. C. H. Hollman, M. B. Katan, and D. Kromhout. Dietary antioxidant flavonoids and risk of coronary heart disease: the Zutphen EIderly Study. Lancet 342: 1007-1011, 1993.

14. Hertog, M. G. L., D. Kromhout, C. Aravanis, H. Blackburn, R. Buzina, F. Fidanza, S. Giampaoli, A. J ansen, A. Menotti, S. Nedeljkovic, M. Pekkarinen, B. S. Simic, H. Toshima, E. J. M. Feskens, P. C. H. Hollman, and M. B. Katan. Flavonoid intake and long-term risk of coronary heart disease and cancer in the seven countries study. Arch. Intern. Med. 155: 381-386, 1995.

15. Hollman, P. C. H., M. V. D. Gaag, M. J . B. Mengelers, J . M. P. Van Trijp, J . H. M. DeVries, and M. B. Katan. Absorption and disposition kinetics of the dietary antioxidant quercetin in man. FreeRadic. Biol. Med. 21: 703- 707, 1996.

16. Husain, S. R., J . Cillard, and P. Cillard. Hydroxyl radical scavenging activity of flavonoids. Phytochemistry (Oxf.) 26: 24892491, 1987.

17. I garashi, K., and M. Ohmuma. Effects of isorhamnetin, rhamnetin, and quercetin on the concentrations of cholesterol and lipoperoxide in the serum and liver and on the blood and liver antioxidative enzyme activities of rats. Biosci. Biotech. Biochem. 59: 595-601, 1995.

18. Ioku, K., T. Tsushida, Y. Takei, N. Nakatani, and J . Terao. Antioxidative activity of quercetin and quercetin monoglucosides in solution and phospholipid bilayers. Biochim. Biophys. Acta 1234: 99- 104, 1995.

19. Manach, C., C. Morand, C. Demigné, O. Texier, F. Régérat, and C. Rémésy. Bioavailability of rutin and quercetin in rats. FEBS Lett. 409: 12-16, 1997.

20. Manach, C., C. Morand, O. Texier, M.-L. Favier, G. Agullo, C. Demigné, F. Régérat, and C. Rémésy. Quercetin metabolites in plasma of rats fed diets containing rutin or quercetin. J . Nutr. 125: 1911-1922, 1995.

21. Manach, C., F. Régérat, O. Texier, G. Agullo, C. Demigné, and C. Rémésy. Bioavailability, metabolism and physiological impact of 4-oxo-flavonoids Nutr. Res. 16: 517-544, 1996

22. Manach, C., O. Texier, F. Régérat, G. Agullo, C. Demigné, and C. Rémésy. Dietary quercetin is recovered in rat plasma as conjugated derivatives of isorhamnetin and quercetin. J . Nutr. Biochem. 7: 375-380, 1996.

23. Middleton, E., J r., and C. Kandaswami. The impact of plant flavonoids on mammalian biology: implications for immunity, inflammation and cancer. In: The Flavonoids: Advances in Re search Since 1986, edited by J . B. Harborne. London: Chapman and Hall, 1993, p. 619-652.

24. Mulder, G. J . Pharmacological effects of drug conjugates: is morphine 6-glucuronide an exception? Trends Pharmacol. Sci. 13: 302-304, 1992.

25. Rice-Evans, C., N. J . Miller, and G. Paganga. Antioxidant properties of phenolic compounds. Trends Plant Sci. 2: 152-159, 1997.

26. Runge-Morris, M. A. Regulation of expression of the rodent cytosolic sulfotransferases. FASE B J . 11: 109-117, 1997.

27. Salah, N., N.J . Miller, G. Paganga, L. Tijburg, G. P. Bolwell, and C. Rice-Evans. Polyphenolic flavanols as scavengers of aqueous phase radicals and as chain-breaking antioxidants. Arch. Biochem. Biophys. 322: 339- 346, 1995.

28. Samman, S., P. M. Lyons-Wall, N. C. Cook, and M. R. Naghii. Minor dietary factors in relation to coronary heart diseaseflavonoids, isoflavones and boron. J . Clin. Biochem. 20: 173-180, 1996.

29. Sfakianos, J ., L. Coward, M. Kirk, and S. Barnes. Intestinal uptake and biliary excretion of the isoflavone genistein in rats. J. Nutr. 127: 1260-1268, 1997.

30. Shaikh, M., S. Martini, J . R. Quiney, P. Baskerville, A. E. La Ville, R. Duffield, P. R. Turner, and B. Lewis. Modified plasma-derived lipoproteins in human atheroschlerotic plaques. Atherosclerosis 69: 165-172, 1988.

31. Shali, N. A., C. G. Curtis, G. M. Powell, and A. B. Roy. Sulphation of the flavonoids quercetin and catechin by rat liver. Xenobiotica 21: 881-893, 1991.

32. Terao, J ., M. Piskula, and Q. Yao. Protective effect of epicatechin, epicatechin gallate, and quercetin on lipid peroxidation in phospholipid bilayers. Arch. Biochem. Biophys. 308: 278-284, 1994.

33. Viana, M., C. Barbas, B. Bonet, M. V. Bonet, M. Castro, M. V. Fraile, and $\mathbf{E}$. Herrera. In vitro effects of flavonoid-rich extract on LDL oxidation. Arteriosclerosis 123: 83-91, 1996.

34. Vinson, J . A., Y. A. Dabbagh, M. M. Serry, and J .J ang. Plant flavonoids, especially tea flavonoids, are powerful antioxidants using an in vitro oxidation model for heart disease. J . Agric. Food Chem. 43: 2800-2802, 1995.

35. Vinson, J . A., J . J ang, Y. A. Dabbagh, M. M. Serry, and S. Cai. Plant polyphenols exhibit lipoprotein-bound antioxidant activity using an in vitro oxidation model for heart disease. J. Agric. Food Chem. 43: 2798-2799, 1995.

36. Williams, C. A., and J . B. Harborne. Flavone and flavonol glycosides. In: TheFlavonoids: Advances in Research Since 1986, edited by J . B. Harborne. London: Chapman and Hall, 1993, p. 337-370.

37. Witzum, J . L., and D. Steinberg. Role of oxidised LDL in atherogenesis. J . Clin. Invest. 88: 1795-1792, 1991.

38. Zhu, B. T., E. L. Ezell, and J . Liehr. Catechol-O-methyltransferase-catalyzed rapid O-methylation of mutagenic flavonoids. J Biol. Chem. 269: 292-299, 1994. 